E International

\title{
Green Growth and Transport
}

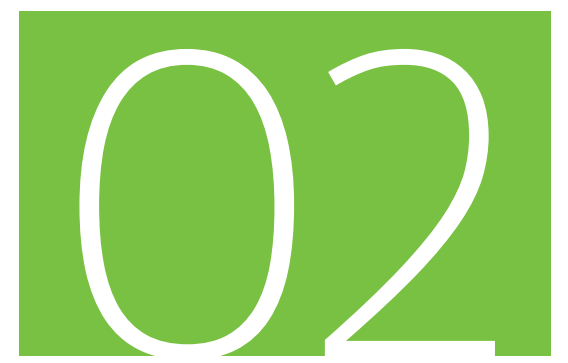

Discussion Paper 2011•02

Stephen PERKINS

International Transport Forum at the OECD, Paris 


\title{
Green Growth and Transport
}

\author{
Discussion Paper No. 2011-02
}

\author{
Stephen PERKI NS
}

International Transport Forum at the OECD, Paris

February 2011 


\section{INTERNATIONAL TRANSPORT FORUM}

The International Transport Forum at the OECD is an intergovernmental organisation with 52 member countries. It acts as a strategic think tank with the objective of helping shape the transport policy agenda on a global level and ensuring that it contributes to economic growth, environmental protection, social inclusion and the preservation of human life and well-being. The International Transport Forum organizes an annual summit of Ministers along with leading representatives from industry, civil society and academia.

The International Transport Forum was created under a Declaration issued by the Council of Ministers of the ECMT (European Conference of Ministers of Transport) at its Ministerial Session in May 2006 under the legal authority of the Protocol of the ECMT, signed in Brussels on 17 October 1953, and legal instruments of the OECD.

The Members of the Forum are: Albania, Armenia, Australia, Austria, Azerbaijan, Belarus, Belgium, Bosnia-Herzegovina, Bulgaria, Canada, Croatia, the Czech Republic, Denmark, Estonia, Finland, France, FYROM, Georgia, Germany, Greece, Hungary, Iceland, India, Ireland, Italy, Japan, Korea, Latvia, Liechtenstein, Lithuania, Luxembourg, Malta, Mexico, Moldova, Montenegro, Netherlands, New Zealand, Norway, Poland, Portugal, Romania, Russia, Serbia, Slovakia, Slovenia, Spain, Sweden, Switzerland, Turkey, Ukraine, the United Kingdom and the United States.

The International Transport Forum's Research Centre gathers statistics and conducts co-operative research programmes addressing all modes of transport. Its findings are widely disseminated and support policymaking in Member countries as well as contributing to the annual summit.

\section{Discussion Papers}

The International Transport Forum's Discussion Paper Series makes economic research, commissioned or carried out at its Research Centre, available to researchers and practitioners. The aim is to contribute to the understanding of the transport sector and to provide inputs to transport policy design. The Discussion Papers are not edited by the International Transport Forum and they reflect the author's opinions alone.

The Discussion Papers can be downloaded from:

www.internationaltransportforum.org/jtrc/DiscussionPapers/jtrcpapers.html

The International Transport Forum's website is at: www.internationaltransportforum.org

For further information on the Discussion Papers and other JTRC activities, please email: itf.contact@oecd.org 


\section{TABLE OF CONTENTS}

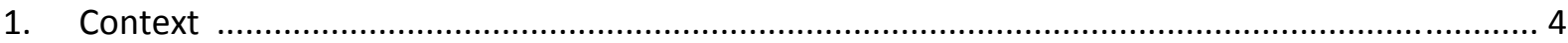

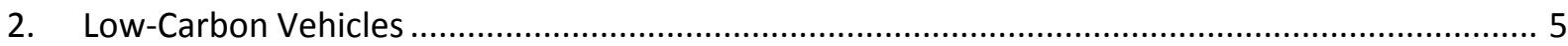

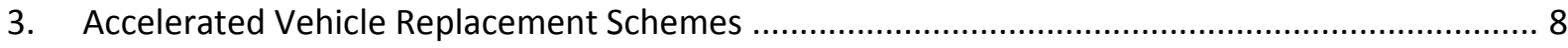

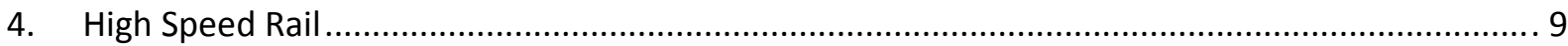

5. Political Economy of Congestion Charges ….......................................................................... 10

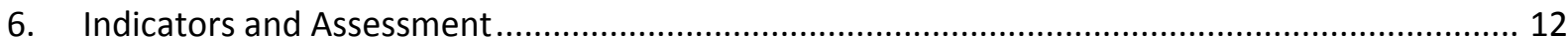

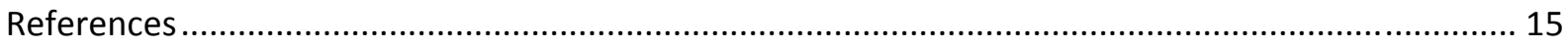

February 2011 


\section{GREEN GROWTH AND TRANSPORT}

\section{CONTEXT}

Transport figures prominently on green growth agendas. The reason is twofold. First, transport has major environmental impacts in terms of greenhouse gas emissions, local air emissions and noise. And managing congestion more effectively is part of the broader agenda for more sustainable development and better use of resources invested in infrastructure. Second, a large part of public expenditure to stimulate green growth is directed at transport sector industries. This concerns most notably alternative vehicles, and particularly electric cars, a key part of strategies to decarbonise transport. Several countries also financed car scrapping and replacement schemes as a short term response to the 2008 financial crisis. The primary goal here was counter-cyclical stimulus for the car manufacturing industry with, in most cases, a secondary goal of reducing $\mathrm{CO}_{2}$ emissions and fuel consumption through fleet renewal. Some governments also include investment in high speed rail as a central element of longer term green growth policies, aiming at a shift in passenger traffic from cars and short haul aviation to rail.

Green growth is a useful paradigm that re-packages several existing concepts, including durable economic activity, reduced environmental impact and sustained growth in high quality jobs, under one banner and in such a way as to frame coherent, cross-sectoral policies. But focusing on green growth as such does not obviate the need for governments to assess policies carefully according to their long-term economic, environmental and social impacts. There are tradeoffs between the various dimensions of green growth. Reducing emissions, for example, comes at a cost to road users and to taxpayers ${ }^{1}$ and as green growth policies spread it may be necessary to review the way the transport sector is taxed and contributes to aggregate tax revenue (Van Dender and Crist 2010).

This section of the report briefly examines policies to support electric vehicles, vehicle replacement schemes and high speed rail and reviews the political economy of introducing congestion charges from experience to date with charging systems around the world. It ends with a review of indicators developed for the assessment of transport investments and policies. Assessment methodology is relatively mature in this sector and the tools developed to support transport sector decision-making in some countries provide a good basis for the assessment of green growth apolicies cross the economy.

\footnotetext{
${ }^{1}$ The recent change in CAFE fuel economy standards in the United States is expected to result in 61.6 billion gallons less fuel consumed from 2012 to 20161 (NHTSA, 2009) after accounting for a slight increase in driving due to lower travel costs. At a constant, combined Federal and State tax rate of 43 cents per gallon, this results in a drop of 26.4 billion dollars from what otherwise could have been expected under the old CAFE regime. This is a major "loss" of revenue. 26.4 billion dollars is equal to $72 \%$ of 2008 US Highway Trust Fund revenues (National Surface Transportation Infrastructure Financing Commission, 2009).
} 


\section{LOW CARBON VEHICLES}

If deep cuts are to be made to greenhouse gas emissions from transport, it is necessary to reduce the carbon-intensity of travel. Reducing travel itself is sometimes justified but it is extremely unlikely that under expected global economic development patterns overall demand will decline. Technological change is therefore crucial. The emerging view is that the focus for decarbonising transport should be first to improve the fuel efficiency of conventional engines and then gradually introduce alternative technologies (ITF 2010).

Designing effective and affordable policies to ensure the deployment of lower carbon technologies in accordance with policy aspirations requires an understanding of how markets for fuel economy work and especially:

- What do consumers take into account in deciding what vehicle to buy?

- What drives manufacturers' decisions on the range of vehicles to offer?

- To what extent does the interaction of supply and demand lead to unsatisfactory fuel economy in relation to climate change objectives?

The value car buyers assign to fuel economy has important implications for policies to reduce $\mathrm{CO}_{2}$ emissions and oil consumption. If consumers undervalue fuel economy over the life of a vehicle, the market will provide too little fuel economy and will under-invest in research and development of energy efficient technologies. At the same time, policies that influence the market via purchase price such as feebates or regulatory policies such as fuel economy standards will have greater leverage on fuel economy than fuel prices. There is considerable agreement that carbon prices should be introduced that are consistent with policy targets. There is considerable disagreement on what to do when tax policies rule out such prices, and also on what extra measures to take when fuel taxes match or exceed the shadow price of emissions. Options are discussed in detail in the report Stimulating Low-Carbon Vehicle Technologies (ITF 2010).

The auto industry needs a regulatory environment that provides certainty for the large capital investments necessary to maximise the fuel economy of new cars; even more so for shifting to new primary energy sources. Standards can provide this certainty and the longer the planning horizon the better. Binding standards for the short term can be complemented by indicative targets for the longer term; the EU standard of $130 \mathrm{gCO}_{2} / \mathrm{km}$ by 2012 for new cars is accompanied by a $95 \mathrm{gCO}_{2} / \mathrm{km}$ target for 2020 which already serves as a reference for complementary measures including vehicle taxes differentiated according to specific $\mathrm{CO}_{2}$ emissions. Standards may outperform fuel taxes in stimulating innovation because they are more closely tied to supply, where innovative effort is concentrated. 
Temporary subsidies can help ultra-low carbon vehicles including electric cars overcome the cost disadvantage of small scale production and compensate for competition that keeps the cost of innovation for internal combustion drive trains relatively low. Subsidy then is designed to ramp up production. ${ }^{2}$ While such subsidies are temporary, ending them is never easy even when the original reason for the subsidy no longer applies. This is a strong argument for avoiding subsidies in the first place. On the other hand, manufacturers risk seeing subsidies for the purchase of electric or fuel cell vehicles cut back before they can recoup the costs of developing the vehicles. These risks are exacerbated by the time it takes to develop new cars of this sort. Governments may be able to guarantee the availability of subsides for 3 or 4 years but just getting new products to market may take much of this time. Electric vehicle subsidies in France, Germany and especially the UK have been programmed to provide at least some security in this respect.

Many governments are funding the creation of markets for ultra-low carbon vehicles. The subsidies available per vehicle can be large, and depending on the vehicle purchased are currently over $\$ 7000$ in Belgium ${ }^{3}$, Canada, China, the Netherlands, the UK and the USA. The UK, for example, has made provision for more than $£ 400$ million ( $€ 472$ million). This includes $£ 80$ million for research, $£ 20$ million for the installation of infrastructure and, around $£ 300$ million ( $€ 354$ million) to support consumer incentives for purchasing over 70000 electric vehicles (extended for the life of the current Parliament). Figure 1 provides a summary for Europe.

Figure 1. Subsidies for Electric Vehicles in Europe: Subsidy available per vehicle and duration of programs announced $1^{\text {st }}$ Quarter 2010

\section{Euros per vehicle}

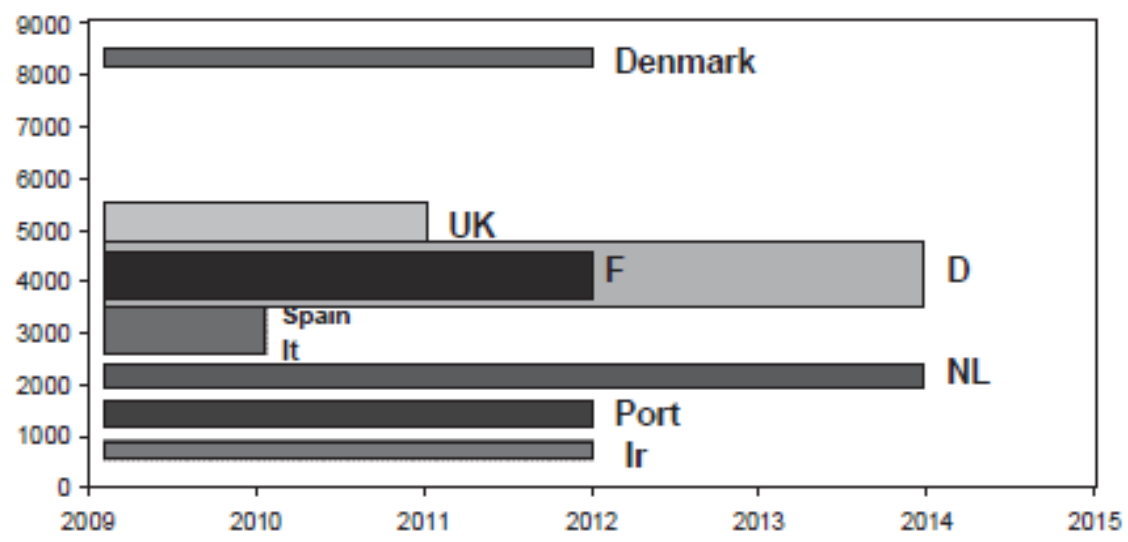

Note: Thickness of bar indicates relative size of markets;

Source: Bastard 2010.

\footnotetext{
${ }^{2}$ This is a separate function to subsidies to R\&D intended to stimulate innovation and justified on the basis of knowledge spillovers.

${ }^{3}$ The highest rate of support currently appears to be available in the Waloon region of Belgium where a 1000 Euro feebate can be combined with national income tax allowance of up to 9000 Euros, capped at $30 \%$ of the value of the vehicle.
} 
Prud'homme (2010) analyses the costs of providing support to consumers for the purchase of electric cars. On the basis of available information on the subsidies available in France $(€ 5000$ per vehicle), costs and performance, his analysis concludes that the present electric car fares much less well than a standard internal combustion engine car. Over the lifetime of a car, an electric vehicle will cost some 12000 Euros more to the consumer, and 14000 Euros more to society. These numbers take into account the difference in maintenance costs and the cost of local pollution. Over the lifetime of a car, $\mathrm{CO}_{2}$ mitigation will range from zero in a country reliant on coal fired electricity like Poland, to a maximum of 19 tons in Sweden or France, provided batteries are recharged at night when the $\mathrm{CO}_{2}$ content of electricity is close to zero. Assuming the average European Union $\mathrm{CO}_{2}$ content of electricity, the $\mathrm{CO}_{2}$ gain of an electric car operating $10000 \mathrm{~km}$ over 15 years will be about 8 tons. The implied cost of saving one ton of $\mathrm{CO}_{2}$ ranges from about 900 Euros to infinity (in extreme cases, the electric car could increase $\mathrm{CO}_{2}$ emissions), with an average of 2500 Euros $^{4}$.

There are large uncertainties for several of the parameter values used but sensitivity analysis changes little. Different discount rates, large increases in fuel taxes and crude oil prices, increase in the electrical efficiency of cars and large decreases in the cost of electric cars and of batteries were modelled. These do have an impact on the relative costs of vehicles and the $\mathrm{CO}_{2}$ gains, but not much. Taken individually, they typically reduce cost differences by 1000 or 2000 Euros. It is only when several of these changes are introduced jointly that the difference in costs is reduced significantly. A $30 \%$ decline in electric car cost and in battery cost plus a $100 \%$ increase in electric efficiency, plus a $12 \%$ per year increase in the price of oil eliminates the extra cost to the consumer but not the socio-economic cost. The probability that all these changes would occur together is not zero, but it is not very high.

One parameter deserves particular attention: mileage. The more $\mathrm{km}$ per year an electric car is driven, the more economic it is. But mileage is constrained by the limited range $(150 \mathrm{~km})$ of electric cars. This means that the electric car market is likely only to concern cars driven many km per year on short trips, and this is reflected in the strategies of major manufacturers. This only accounts for about $10 \%$ of the automobile markets according to industry estimates. The electric car is therefore more likely to be a niche product than a general substitute for the internal combustion engine, except in hybrid form, for some time to come.

Prud'homme concludes that "the electric car appears to be a gamble on the part of producers and governments. Until massive cost and efficiency improvements are achieved, it will require massive subsidies. If they are achieved, and achieved rapidly, this gamble might pay. If not, a lot of resources will have been wasted. In this case, a fraction of these resources would have made it possible to reduce $\mathrm{CO}_{2}$ by much larger amounts." If, on the other hand, technology improves more rapidly than envisaged, the prize is potentially very large.

The risks associated with subsidies induce rather negative attitudes towards them in most economists. Reluctant support is based on the premise that breakthrough technologies are needed if the energy base of transport is to be transformed. Innovation in the car industry is not of the "lone creative entrepreneur" type but the transformative efforts required for very low carbon transport should not

\footnotetext{
${ }^{4}$ Note that electricity production is included in the European Emissions Trading System. Assuming a well functioning market for permits, the $\mathrm{CO} 2$ emissions from electricity can be ignored as increased emissions from new demand for electricity for transport will be compensated by emissions reductions elsewhere among the trading sectors.
} 
necessarily be expected to emerge from industry by itself. Policy intervention then is needed, even given tangible risks that it turns out more costly than hoped for, for as long as the risks of not attaining policy targets are deemed larger than the risks of intervention.

\section{ACCELERATED VEHICLE REPLACEMENT SCHEMES}

Car scrapping schemes have been introduced in many countries in periods of economic downturn. These programs can have a number of aims:

- $\quad$ Direct effects:

1. Support for the automobile industry (manufacturers, dealerships and other related businesses) to decrease the likelihood of mass lay-offs;

2. Stimulating increased consumer spending;

- Indirect effects through substitution of new vehicles for poorer performing older models, and in some schemes removing older vehicles without replacement:

1. Reducing dependence on foreign oil;

2. Reducing $\mathrm{CO}_{2}$ emissions;

3. Improvement of air quality;

4. Improving road safety.

The real-world impact of these schemes is not clear a priori. Surprisingly, the value of the schemes in terms of employment and stimulus to the economy has been very little studied. ECMT (99) found extremely high costs per ton of $\mathrm{CO}_{2}$ mitigated for most schemes introduced in the 1980s and 90s. Small scale systems focussing on removing the very worst vehicles from circulation, including some of the "cash for clunkers" schemes in the US and support for replacement of old buses in Italy, performed best. Scaling up to provide significant stimulus to the car industry destroyed cost-effectiveness in terms of environmental benefits. Much better alternative instruments are available for implementing policies for environmental protection, safety and energy security.

TNO (2010) examined scrapping schemes introduced in the USA, Germany and France to provide economic stimulus in the wake of the 2008 financial crisis. Each was designed to promote fuel economy and mitigation of $\mathrm{CO}_{2}$ emissions by the conditions attached to the grants available for replacing vehicles. The analysis also covered NOx emissions and safety benefits from accelerated deployment of recent active safety technologies. The study found that the cost of the schemes in terms of the value of the resources destroyed in scrapping cars ( $\$ 1 \mathrm{bn}$ in the USA, $€ 3.2 \mathrm{bn}$ in Germany) exceeded the benefits attributable to the indirect benefits in all cases. $\mathrm{CO}_{2}$ mitigation contributed very little to the benefit side of the calculation. Safety and especially NOx mitigation contributed the bulk of the benefits. In the best 
case, the US CARS program, the indirect benefits roughly balanced the resource cost. The benefits are somewhat underestimated because particulate and other noxious emissions were not included in the analysis; neither were the potential direct benefits in terms of economic stimulus.

If the last three decades are a guide, accelerated vehicle renewal programs can be expected to feature in many future economic stimulus programs. Designing them to contribute to greener growth is therefore important. The UK government rightly argued that its 2008-10 scrappage scheme was designed to stimulate the economy not green it, but unfortunately missed the opportunity to steer purchases towards lower carbon and safer vehicles by deciding not to make eligibility for subsidies conditional on performance.

The targeting of vehicles to be scrapped plays a major role in determining the balance of benefits. With the three schemes examined by TNO, those that restricted subsidies to replacing older vehicles achieved larger NOx mitigation benefits per dollar or Euro spent. Conversely, including newer vehicles for replacement increases the mitigation of $\mathrm{CO}_{2}$ emissions because these vehicles would have been driven for more years over greater distances than older scrapped vehicles. The incremental improvements therefore accrue over a longer horizon. Exactly how large the benefits are likely to be from any scheme depends on the gap in performance between the vehicles scrapped and the replacement vehicles. For safety in particular there can be large discontinuities as new technologies are introduced. Thus similar schemes introduced at different times may have very different impacts.

\section{HIGH SPEED RAIL INVESTMENTS}

Investments in high speed rail are frequently cited as contributing to the green growth agenda. High speed rail investments figure prominently in projects launched under France's "Grenelle Environnement ${ }^{5}$, under which the Government is committed to launching the construction of $2000 \mathrm{~km}$ of new high speed lines by 2020. The UK Coalition Programme for Government (UK 2010) states that "We will establish a high speed rail network as part of our programme of measures to fulfil our joint ambitions for creating a low carbon economy." The first phase of the programme (London to Birmingham) will require an investment of $£ 17 \mathrm{Bn}$.

High speed rail can compete effectively with transport by passenger car and, more significantly, air over distances up to $1000 \mathrm{~km}$ where traffic is sufficiently dense, i.e. between major centres of population. For example, it currently holds over $90 \%$ of the combined air and rail markets between Paris and Lyon and Paris and Avignon. In general, where rail journey times can be brought close to three hours, high speed rail can be expected to take a major share of origin-destination aviation markets (Nash 2009). Nash finds the breakeven volume of passengers to justify a new high-speed line is very variable, ranging from 3 million to 17 million in the first year of operation, but typically even under favourable conditions at least 9 million passengers per annum will be needed. The existing French high-speed lines exceeded this

\footnotetext{
${ }^{5}$ Environment Round Table, instigated by the President of France, Nicolas Sarkozy, in 2007 to define the key points of government policy on ecological and sustainable development issues for the coming five years. http://www.legrenelle-environnement.fr/-Version-anglaise-.html
} 
volume. But it is clear that some proposals are being developed where traffic is very much less dense. The most important variable in determining the breakeven volume is the construction cost, which varies enormously according to circumstances.

Benefits in terms of both $\mathrm{CO}_{2}$ emissions mitigation and the stimulation of employment deserve close examination as public credits are required for the very large long-term investments in high speed track, even in cases where projects break even. The issue of wider economic benefits is one of the hardest to tackle (see final section). Such benefits could be significant, but vary widely from case to case. A specific study of each case is required.

Kageson (2009) has undertaken a detailed comparison of $\mathrm{CO}_{2}$ emissions and other environmental impacts from high speed rail and competing modes of transport. He concludes that investment in high speed rail is under most circumstances likely to reduce greenhouse gases from traffic compared to a situation when the line was not built, but the reduction is small and it may take decades for it to compensate for the emissions caused by construction.

In cases where anticipated journey volumes are low it is not only difficult to justify the investment in economical terms, but it may also be hard to defend the project from an environmental point of view as it will take too long for traffic to offset the emissions caused by building the line. Under such circumstances it may be better to upgrade an existing line to increase capacity and accommodate somewhat higher speeds.

Speed is a critical factor. The energy needed for acceleration is determined by the weight of the train and the final speed. This kinetic energy increases with the square of the speed, as does aerodynamic resistance (UIC 2008). Therefore, moving a train at $300 \mathrm{~km} / \mathrm{h}$ will require roughly four times the energy needed for a trip by conventional rail at $150 \mathrm{~km} / \mathrm{h}$.

Nash (2009) concludes that environmental benefits are unlikely to be a significant part of the case for high-speed rail when all relevant factors are considered, but nor are they a strong argument against it provided that high load factors can be achieved and the infrastructure itself can be accommodated without excessive environmental damage. A key factor here is the approach to cities, where the choice may be between use of conventional tracks at reduced speed or expensive tunnelling.

\section{THE POLITICAL ECONOMY OF CONGESTION CHARGES}

Managing congestion is central to sustainable transport infrastructure policies. This issue is most prominent on the roads. Most studies of the external costs of road use find $\mathrm{CO}_{2}$ emissions to be small relative to other types of externality, especially congestion (Figure 2). This is not to say that the cost of climate change is not large, rather there are other more pressing market failures in transport (Small and Van Dender 2007). 
Figure 2. $\mathrm{CO}_{2}$ Relative to Other External Costs

(US cents/mile)

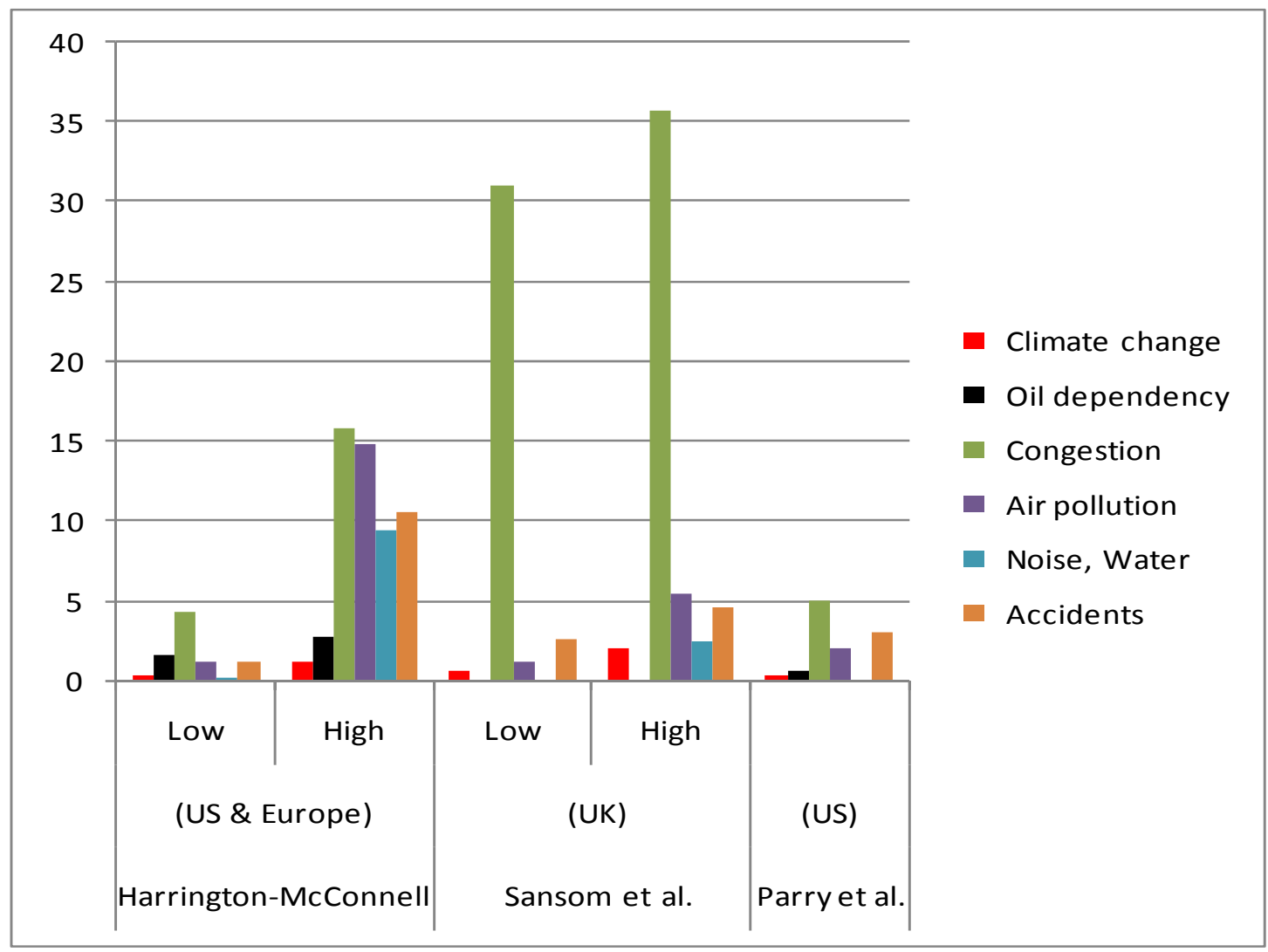

Source: Small and Van Dender (2007).

Recent economic evidence reviewed by the International Transport Forum (ITF 2010b) strengthens the case for using charges to bring congestion closer to efficient levels. The key to successful implementation of congestion charges is to get the policy accepted; and lessons on the political economy of introducing congestion charges successfully in London, Stockholm and Singapore and value pricing ${ }^{6}$ on US some highways may prove insightful for the development of green growth policies in other sectors. Reasons for the withdrawal of plans for national congestion charging systems in the UK and the Netherlands are equally relevant.

Acceptance is dynamic. It can be managed to an extent and depends on a number of factors, including the effectiveness of the measures introduced - in this case in delivering more reliable and faster journey times. Ensuring acceptance may require giving up some of the benefits of a theoretically ideal system. Less-than-ideal systems such as simple pricing cordons and value pricing schemes can still be satisfactory. Rule-based systems for changing prices (e.g. maintaining pre-determined levels of speeds as in Singapore and the dynamic pricing applied to the I-15 freeway in San Diego) appear to be more popular

\footnotetext{
${ }^{6}$ Value pricing is the term given to tolled lanes on US highways added to existing roads either through building additional capacity or giving access to existing lanes that are otherwise reserved for high occupancy vehicles only.
} 
than those requiring political discretion, i.e. periodic agreement by elected officials on charge levels/increases. Ancillary benefits, including reduced environmental impacts, can in some cases have an impact on how much to charge and should always be included in assessments, but they are not the principal goal of congestion charging mechanisms. Focusing on reducing $\mathrm{CO}_{2}$ emissions when arguing for the introduction of congestion charges risks rejection.

Congestion charges potentially raise substantial amounts of revenue, but the systems are costly to run as well. This renders promises of revenue neutrality with new congestion charges counter-productive, as equalising gross revenues implies lower net revenues when the unavoidable costs of congestion charging systems are taken into account. In general, emphasizing revenue neutrality reduces policy flexibility. It may appear to be a requirement for getting public and political support but transparency and accountability in revenue use is at least as important for acceptance. This, rather than revenue neutrality, was one of the keys to success in London.

The lessons from recent experience with the introduction of charging systems can be summarised as follows.

- Only turn to congestion charging if congestion is serious and clearly perceived to be serious by the public. Congestion charging systems are expensive to operate, accounting for 10 to $30 \%$ of revenues, and only justifiable where congestion is severe.

- Significant efforts need to be put into ensuring that there is sufficient awareness of the problem before charging is implemented.

- Do not confuse objectives. There are cheaper ways to raise revenues and to protect the environment. Congestion charging is only applicable nationwide if congestion is a problem nationwide. If the primary objective is to make road taxes fairer, e.g. by charging foreign trucks on the same basis as domestic vehicles, or replacing a national tax that raises tax competition problems with neighbouring countries, more cost-effective alternatives are likely to be available.

- Do not phase-in charges from a low base. This will fail to cut congestion, undermining support, and fuel fears that real motive for the charge is revenue raising.

- Do not promise revenue neutrality. Instead provide Transparency and accountability

Many of these lessons are relevant to green growth policies more widely, particularly when they concern pricing the use of resources or otherwise improving systems of taxation.

\section{INDICATORS AND ASSESSMENT}

The development of economic and environmental appraisal techniques is relatively mature in the transport sector, at least in the countries where appraisal is routine. This reflects a number of factors: the potential for transport infrastructure to have major and largely irreversible environmental impacts; the 
spatial and economic structuring effects of major transport investments; and the spatial scale of impacts with some projects, along corridors hundreds of kilometres long. Strategic environmental assessment was developed in large part for the evaluation of major transport infrastructure programs. Evaluation techniques and decision-making support tools are now employed systematically for transport projects, programs and policies in the countries of North West Europe, Japan, Korea and in Australasia.

The core of transport appraisal is cost-benefit assessment (CBA). In principle CBA is equally applicable to private and public projects, but because of its focus on social welfare (instead of, e.g., profits) the method is most frequently used for public decision-making. CBA for transport infrastructure measures benefits through transport users' willingness-to-pay, i.e. it measures direct benefits. The choice to work with willingness-to-pay reflects the welfare economic fundamentals of the method; what matters in the end are consumer benefits. The choice to focus on direct user benefits is one of practicality. A transport infrastructure project will affect users' travel times and more generally their benefits from travel. Measuring these direct benefits is far easier than tracing the ultimate incidence of project impacts throughout the economy. However, this comes at a cost in terms of scope and policy-relevance. This is examined in detail in ITF (2011).

Although direct benefits usually equate to total benefits this is not always the case. Agglomeration benefits (the benefits in terms of thicker labour and product markets and information spillovers) are not captured in CBA as these benefits are external to users. Agglomeration benefits and transformational effects are often thought to be critical to projects in green growth investment portfolios, and notably for high speed rail. However, the evidence base is not strong and as Nash (2009) points out they vary greatly from project to project. Agglomeration effects are smaller for high speed rail than for large urban rail projects, like Crossrail in London, which are much more relevant to development of the labour market.

CBA is similarly limited in its ability to evaluate environmental externalities. Shadow prices can be attached to some environmental costs, including $\mathrm{CO}_{2}$ emissions, for potential incorporation in CBA. Given the range of different views on the appropriate shadow price for $\mathrm{CO}_{2}$ emissions, depending on whether this is based on damage estimates, mitigation costs or political targets for abatement, it is advisable to make this part of overall impact assessments transparent rather than simply integrated in a compound benefit-cost ratio.

Multi-criteria analysis (MCA) makes such a compound calculation, using CBA for a project's impacts on economic efficiency and then monetising the less tangible impacts to derive an overall quantitative (usually monetary) indicator of the broader net value of the project. MCA is itself restrictive in that for some impacts, satisfactorily objective monetisation techniques have so proved elusive (e.g. for landscape and severance impacts). The strength of MCA is that it enables different weights to be attached to different aspects of the evaluation but this is also its great weakness. Decisions on the weighting criteria employed can be critical in determining outcomes but they tend to be hidden in the detail of the analysis. Although scenarios can be produced on the basis of different weightings to illustrate their impact, it is difficult to present this to decision-makers in a way that is sufficiently concise and transparent.

The response in some countries has been to employ an MCA approach without deriving a single quantitative indicator of net value. An example is the UK's use of "appraisal summary tables" under the New Approach to Appraisal introduced in 1998 for road projects. This has since been developed to cover investments in all modes and incorporates strategic environmental assessment for large projects. The appraisal summary table takes the form of a single page designed to highlight information relevant to current economic and other policy objectives. It includes statements of net present value of the project to users and to government and monetary indicators of value in improving safety and accessibility. 
Environmental impacts are listed in a variety of ways. Noise impacts are recorded by the number of properties affected. Climate change impacts are indicated by tons of $\mathrm{CO}_{2}$ added or avoided. Other effects are given a simple score depending on whether they are expected to be minor, significant or a major element for consideration. The list of factors covered can be added to according to current government policy priorities and includes impacts on landscapes, heritage sites, biodiversity, physical fitness, reliability, wider economic impacts, severance and land use policy. No weighting is applied to the different indicators. The decision maker is left to make the trade-offs involved in choosing whether to advance the project.

Tensions between the broad policy planning level and the appraisal level can and do arise in every country. What happens, for example, to projects that pass a CBA test but that lead to increased carbon emissions (e.g. extra capacity at severely congested hub airports), when the strategic policy choice is to decarbonise the transport sector? Or to projects that do not pass a CBA test but are thought to contribute to decarbonisation (e.g. some high-speed rail projects)? It seems unreasonable to halt every project that increases $\mathrm{CO}_{2}$-emissions even when the broad goal is to reduce the transport sector's emissions, just as it seems unreasonable to accept all projects that reduce carbon-emission irrespective of cost. CBA can be extremely useful in quantifying this tension between an individual project's merits and the broad thrust of policy. Appraisal summary tables of the kind routinely employed for publicly funded transport projects and policies in the UK provide a model for assessing the effectiveness of green growth policies. 


\section{REFERENCES}

Bastard (2010), The Impact of Economic Instruments on the Auto Industry and the Consequences of Fragmenting Markets, Luc Bastard, in ITF (2010) http://internationaltransportforum.org/itrc/DiscussionPapers/DP201008.pdf .

ECMT (1999), Cleaner Cars: Fleet Renewal and Scrappage Schemes, ECMT, OECD Publishing 1999. http://internationaltransportforum.org/europe/ecmt/pubpdf/99Scrappage.pdf

ITF (2010), Stimulating Low-Carbon Vehicle Technologies, International Transport Forum, OECD Publishing 2010; Summary at http://internationaltransportforum.org/itrc/DiscussionPapers/DP201013.pdf.

ITF (2010b), Implementing Congestion Charges, International Transport Forum, OECD Publishing 2010; Summary at http://internationaltransportforum.org/itrc/DiscussionPapers/DP201012.pdf

ITF (2011), Improving the Practice of Transport Appraisal, International Transport Forum, OECD Publishing 2011. Summary at http://internationaltransportforum.org/itrc/DiscussionPapers/ .

Kageson (2009), Environmental Aspects of Inter-City Passenger Transport, Per Kageson in The Future for Interurban Passenger Transport, International Transport Forum, OECD Publishing 2010.

http://internationaltransportforum.org/itrc/DiscussionPapers/DP200928.pdf

Nash (2009), When to Invest in High-Speed Rail Links and Networks?, Chris Nash in The Future for Interurban Passenger Transport, International Transport Forum, OECD Publishing 2010.

http://internationaltransportforum.org/itrc/DiscussionPapers/DP200916.pdf

Small, K and K. Van Dender (2007) Long Run Trends in Transport Demand, Fuel Price Elasticities, and Implications of the Oil Outlook for Transport Policy, in Oil Dependence: Is Transport Running Out of Affordable Fuel, International Transport Forum, OECD Publishing 2008.

http://internationaltransportforum.org/jtrc/DiscussionPapers/DiscussionPaper16.pdf

TNO (2010), Vehicle Scrapping Schemes Impact on $\mathrm{CO}_{2}$, NOx and Safety, Global Fuel Economy Initiative, 2011. http://www.globalfueleconomy.org/publications/Pages/WorkingPapers.aspx

UIC (2008), Process, Power, people. Energy Efficiency for Railway Managers. Union Internationale des Chemin de fer, Paris.

UK (2010) The Coalition: Our Programme for Government, HM Government 2010.

Van Dender and Crist (2010), What does improved fuel economy cost consumers and taxpayers?, Kurt Van Dender and Philippe Christ, International Transport Forum Discussion Paper 2011-1, draft presented to ITF-KOTI Green Growth Workshop http://internationaltransportforum.org/Proceedings/GreenGrowth2010/VanDender.pdf 
E International

International Transport Forum

2 rue André Pascal

75775 Paris Cedex 16

itf.contact@oecd.org

www.internationaltransportforum.org 